\title{
Unexpected Crohn's Disease after a Free Gastrointestinal Perforation
}

\section{René Rodríguez-Gutiérrez, Mario Rodarte-Shade, José Gerardo González-González}

\section{CASE REPORT}

A 46-year-old male with history of chronic intermittent diarrhea and chronic lower-back pain was presented to our clinic with sudden diffuse abdominal pain irradiated to both shoulders. He had been on nonsteroidal antiinflammatory drugs (NSAIDs) and prednisone (5-20 mg POq24h) for three years with partial back pain relief. Physical examination revealed diffusetenderness and rigid abdomen with no bowel sounds. X-ray of chest showed a pneumoperitoneum (Figure 1). A diagnosis of a possible peptic ulcer perforation was made. He was immediately managed with intravenous volume, nasogastric tube, intravenous proton-pump inhibitor (PPI), broadspectrum antibiotics, and urgent laparotomy. During surgery a $3-4 \mathrm{~mm}$ perforation $50 \mathrm{~cm}$ before the ileocecal valve was found along with multiple focal mucosal ulcerations (Figure 2). Partial bowel resection with an ileostomy was made. Erythrocyte sedimentation rate and C-reactive protein were elevated and a macrocytic anemia with low levels of serum B12 was documented. The ileum biopsy revealed focal ulcerations across the ileum wall with acute/chronic inflammation and no sign

René Rodríguez-Gutiérrez¹, Mario Rodarte-Shade², José Gerardo González-González ${ }^{3}$

Affiliations: ${ }^{1} \mathrm{MD}$, Chief Resident, Department of Internal Medicine, University Hospital "Dr. José E. González" Universidad Autonoma de Nuevo León, Monterrey, MÉXICO; ${ }^{2} \mathrm{MD}$, Chief Resident, Surgery Department, Hospital San José, Instituto Teconológico y de Estudios Superiores de Monterrey, Monterrey, MÉXICO; ${ }^{3} \mathrm{MD}$, Ph.D, Vice Dean of Research and Professor of Internal Medicine, University Hospital "Dr. José E. González" Universidad Autonoma de Nuevo León, Monterrey, MÉXICO.

Corresponding Author: René Rodríguez-Gutiérrez, MD, Department of Internal Medicine, Dr. José E. González" University Hospital Universidad Autonoma de Nuevo León, Monterrey, MÉXICO; Ph: +521 811474 9146; Fax: 5281 8348 3066; Email: renerodriguez@investigacion-meduanl. com

Received: 14 August 2012

Accepted: 27 July 2013

Published: 01 December 2013

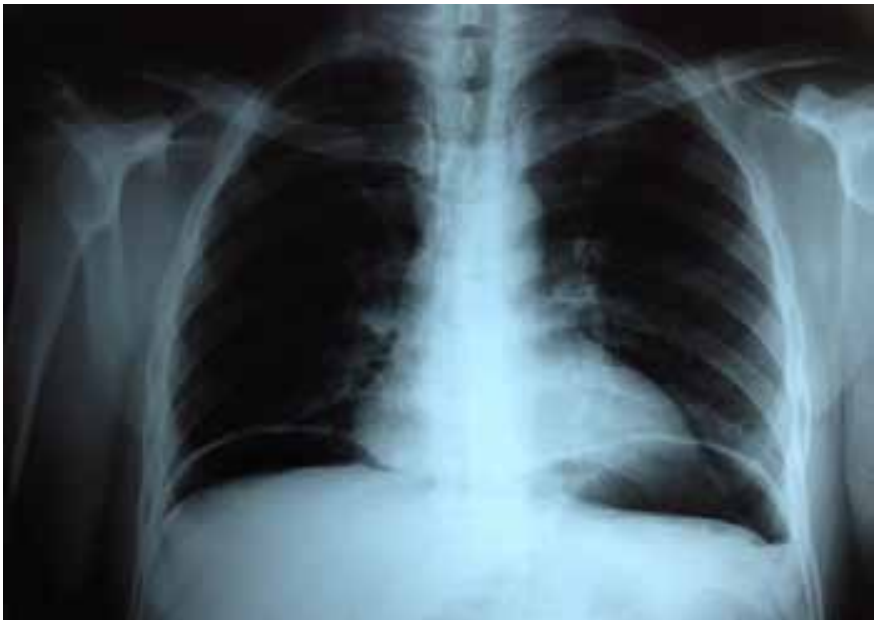

Figure 1: Chest X-ray showing air under both diaphragms confirming the presence of pneumoperitoneum.

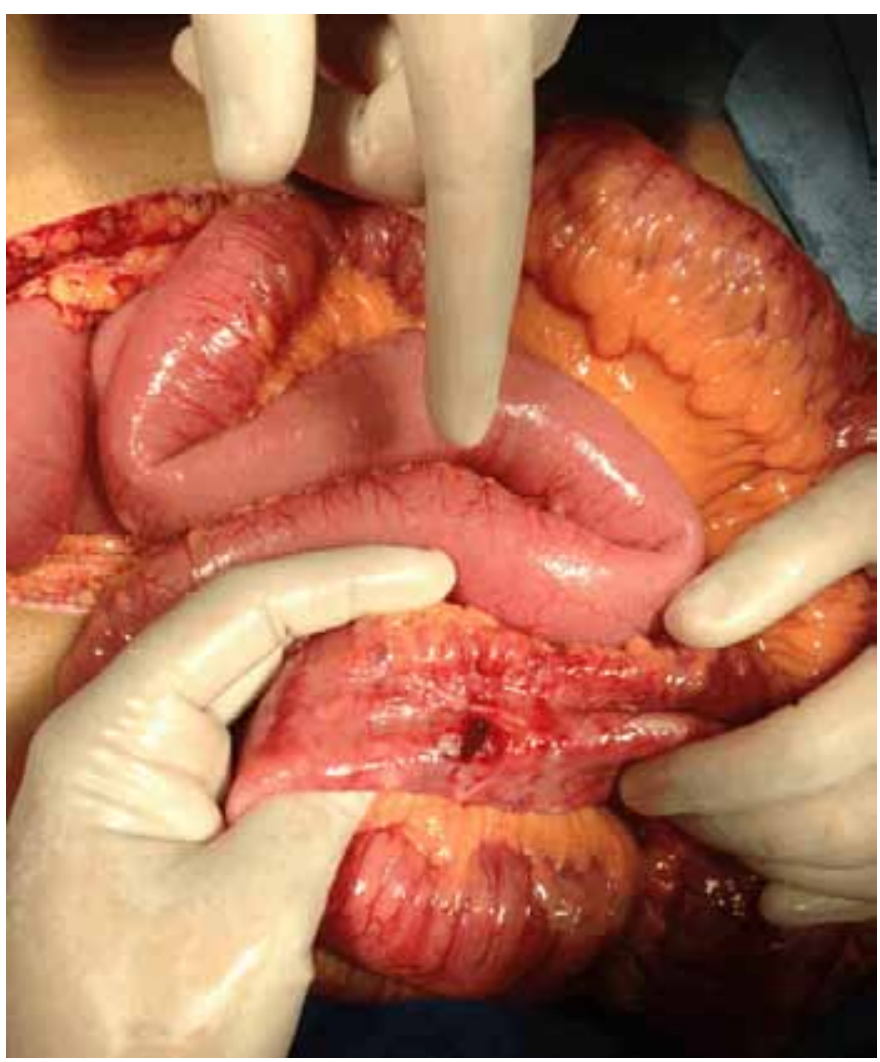

Figure 2: Ileum perforation $50 \mathrm{~cm}$ before the ileocecal valve. 
of malignancy. Ziehl-Neelsen and culture for tuberculosis were negative. Colonoscopy revealed focal ulcerations and pseudopolyps adjacent to areas of normal appearing mucosa with the characteristic cobblestone appearance and the same pathologic findings of the previous ileum biopsy. The compatible clinical history along with the laboratory, endoscopic and pathology findings made the final diagnosis of Crohn's disease. Treatment with azathioprine and mesalamine was initiated. The patient had an uneventful recovery and at a six-month followup he was asymptomatic. An unexpected diagnosis of Crohn's disease was made, probably partially masked over the last three years by the chronic glucocorticoid therapy used for the chronic lower-back pain that was finally attributed to a spinal disc hernia. Human Leukocyte Antigen (HLA)-B27 was negative and there was no sign of spondylitis or sacroiliitis.

\section{DISCUSSION}

Crohn's disease is a chronic illness of uncertain etiology that is characterized by a transmural inflammation of the entire gastrointestinal tract. Crohn's complications are fistulae, localized peritonitis, abscesses, bowel obstructions, gastrointestinal perforation, and hemorrhage. Of them free gastrointestinal perforation, which is a life-threatening complication, is the most rare and described only in $\mathbf{1 - 2 \%}$ of these patients. It is more common as the initial manifestation of the illness, but has also been described during the course of the disease [1]. Most of the patients present instead with an intraabdominal abscesses or fistulae. The most common site of free perforation is the ileum or jejunum and chronic steroid use has been proposed as risk factor for perforation. Pneumoperitoneum, as found in this case, is an uncommon feature of small intestine perforation [2]. Diagnosis is made by the characteristic clinical presentation of acute abdominal pain along with acute systemic inflammatory response syndrome or sepsis and the characteristic findings on the chest and abdominal $\mathrm{X}$-rays or computed tomography. Immediate management to achieve hemodynamic stability with high-volume intravenous fluids and sometimes catecholamines along with broad-spectrum antibiotics is essential. Nevertheless, urgent surgical management with exploratory laparotomy is the cornerstone of the treatment. Prognosis compared to ulcerative colitis perforation is formidable with a mortality rate of less than $5 \%$ if managed promptly [3]. In this case, the steroids that could have treated and "masked" the illness for a long time could have also been the triggering cause of the gastrointestinal perforation.

\section{CONCLUSION}

Free gastrointestinal perforation in Crohn's disease is an unusual but life-threatening complication that requires prompt diagnosis and urgent management with intravenous fluids, broad-spectrum antibiotics, and immediate exploratory laparotomy. Good prognosis is inversely proportional to the time taken for an appropriate treatment.

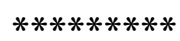

Rodríguez-Gutiérrez R, Rodarte-Shade M, GonzálezGonzález JG. Unexpected Crohn's Disease after a Free Gastrointestinal Perforation. International Journal of Case Reports and Images 2013;4(12):742-744.

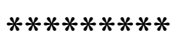

doi:10.5348/ijcri-2013-12-425-CL-19

\section{Author Contributions}

René Rodriguez-Gutierrez - Served as the principal investigator and made substantial contributions in the conception, design and acquisition of the data, Drafting and revising it critically for important intellectual content, Approved the final version to be published

Mario Rodarte-Shade - Made substantial contributions in the conception, design and acquisition of the data, Drafting and revising it critically for important intellectual content, Approved the final version to be published José Gerardo González-González - Made substantial contributions in the conception, design and acquisition of the data, Drafting and revising it critically for important intellectual content, Approved the final version to be published

\section{Guarantor}

The corresponding author is the guarantor of submission.

\section{Conflict of Interest}

Authors declare no conflict of interest.

\section{Copyright}

(C) René Rodriguez-Gutierrez et al. 2013; This article is distributed under the terms of Creative Commons attribution 3.0 License which permits unrestricted use, distribution and reproduction in any means provided the original authors and original publisher are properly credited. (Please see www.ijcasereportsandimages.com/ copyright-policy.php for more information.)

\section{REFERENCES}

1. Freeman HJ. Spontaneous free perforation of the small intestine in Crohn's disease. Can J Gastroenterol 2002 Jan;16(1):23-7. 
2. Werbin N, Haddad R, Greenberg R, Karin E, Skornick Y. Free perforation in Crohn's disease. Isr Med Assoc J 2003 Mar;5(3):175-7.

3. Greenstein AJ, Sachar DB, Mann D, Lachman P, Heimann T, Aufses AH Jr. Spontaneous free perforation and perforated abscess in 30 patients with Crohn's disease. Ann Surg 1987 Jan;205(1):72-6.

Access full text article on other devices

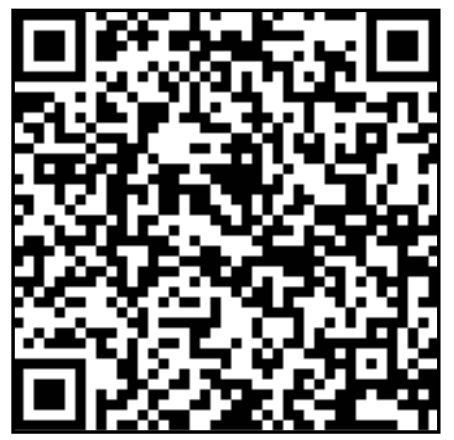

Access PDF of article on other devices

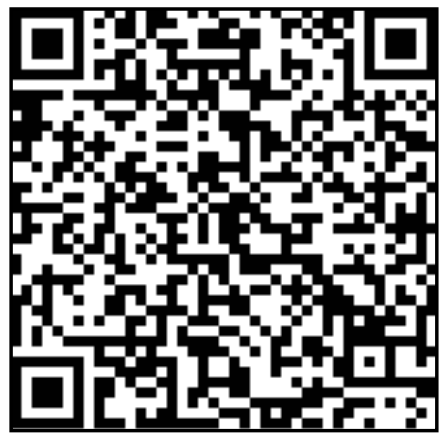

